\title{
ESCUELA PÚBLICA "CARME DE ABAIXO". SANTIAGO DE COMPOSTELA (GALICIA, ESPAÑA)
}

\author{
"CARMEN DE ABAIXO" PUBLIC SCHOOL, SANTIAGO DE COMPOSTELA. GALICIA, SPAIN)
}

\author{
G. Grassi, C. García Braña y N. Dego, Arquitectos \\ ESPAÑA
}

Fecha de recepción: 21-VII-95

$142-155$

\author{
RESUMEN \\ En el conjunto arquitectónico formado por el edificio escolar \\ "Carme de Abaixo" vuelve a insistirse en las formas \\ canónicas de antaño, sus dimensiones y volúmenes. Se da \\ prioridad al sistema constructivo en piedra, material, por \\ otra parte, capaz de garantizar la solidez en este tipo de \\ construcción.
}

\section{SUMMARY}

New emphasis has been made in the canonical forms, dimensions and volumes of former times in the architectural complex formed by the "Carmen de Abaixo" school building. Priority is given to the stone construction methods, a material that is also able to assure solidity of this type of construction.

El terreno destinado a la escuela se encuentra en el margen del perímetro habitado, inmediatamente después del límite de la nueva edificación (en el "Plan Especial" se acentúa esta condición de límite por las intervenciones en edificios previstas)

Se trata de un huerto-jardín de mediana dimensión, con un notable número de árboles de distintas especies, incluso distintos árboles frutales.

El edificio escolar está en el centro del terreno, en un claro relativamente amplio (para no sacrificar árboles importantes) y unido a la rúa Entregaleras mediante un pórtico rectilíneo que loatraviesa transversalmente de Este a Oeste y que constituye uno de los ejes de simetría sobre el que está construida la figura arquitectónica del edificio.

Los dos segmentos opuestos del pórtico incluyen, por una parte, el aula polivalente $\left(120 \mathrm{~m}^{2}\right)$ y por otra, el patio cubierto $\left(125 \mathrm{~m}^{2}\right)$ y la entrada a la escuela por la vía pública.

A continuación de este último segmento, además de la rúa Entregaleras, encontramos, a lo largo del mismo porticado, los espacios cubiertos relativos a la actividad deportiva escolar: el gimnasio $\left(240 \mathrm{~m}^{2}\right)$ y la pista polideportiva, de $40 \times 20 \mathrm{~m}$. Ambas incluidas en el "Plan Especial de Equipamiento Deportivo, etc. De Galeras-Santa Isabel. PE-13".

Como ya hemos dicho anteriormente, el conjunto arquitectónico del edificio escolar está construido sobre dos ejes de simetría normales entre sí: se trata, por ello, de un edificio de planta central, cuyos frentes están orientados, aproximadamente, según los puntos cardinales.

Se trata de cuatro torres dispuestas en cuadrado y unidas entre sí por un volumen equivalente. Esto significa, desde el punto de vista del proyecto de utilización de las partes, cuatro aulas normales en los vértices, más un aula polivalente en el centro, por tres plantas.

La figura arquitectónica resultante de este conjunto distributivo es inmediatamente reconocible y relativamente simple. Las cuatro torres remiten a las formas canónicas del "Castillo", pero su dimensión, junto con la del cuerpo central, remite, si acaso, a la interpretación que se dio en 

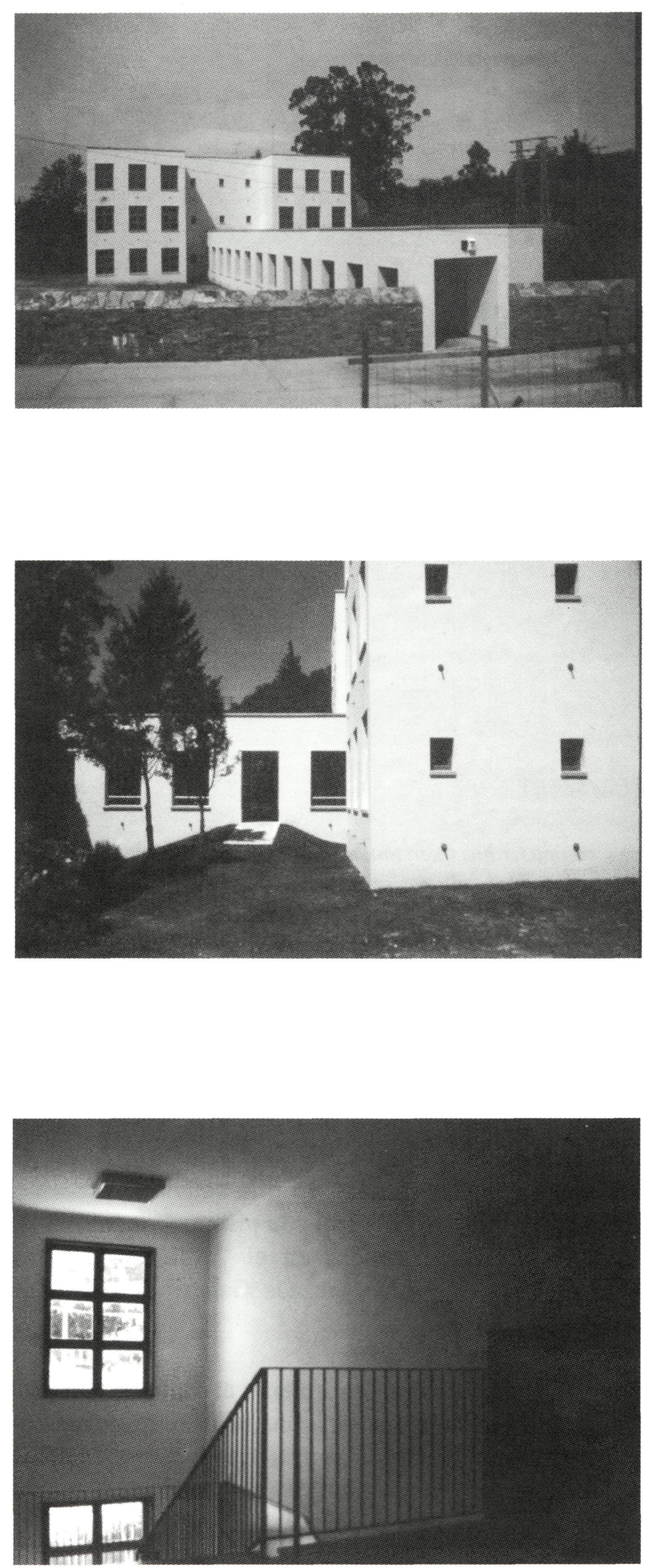

el siglo pasado de esa forma canónica, especialmente en el estudio de nuevas tipologías para las villas suburbanas.

Por otra parte, no demasiado lejos, un poco más allá del río Sarela, encontramos un edificio resquebrajado, precisamente una vieja villa, cuyas dimensiones y articulación
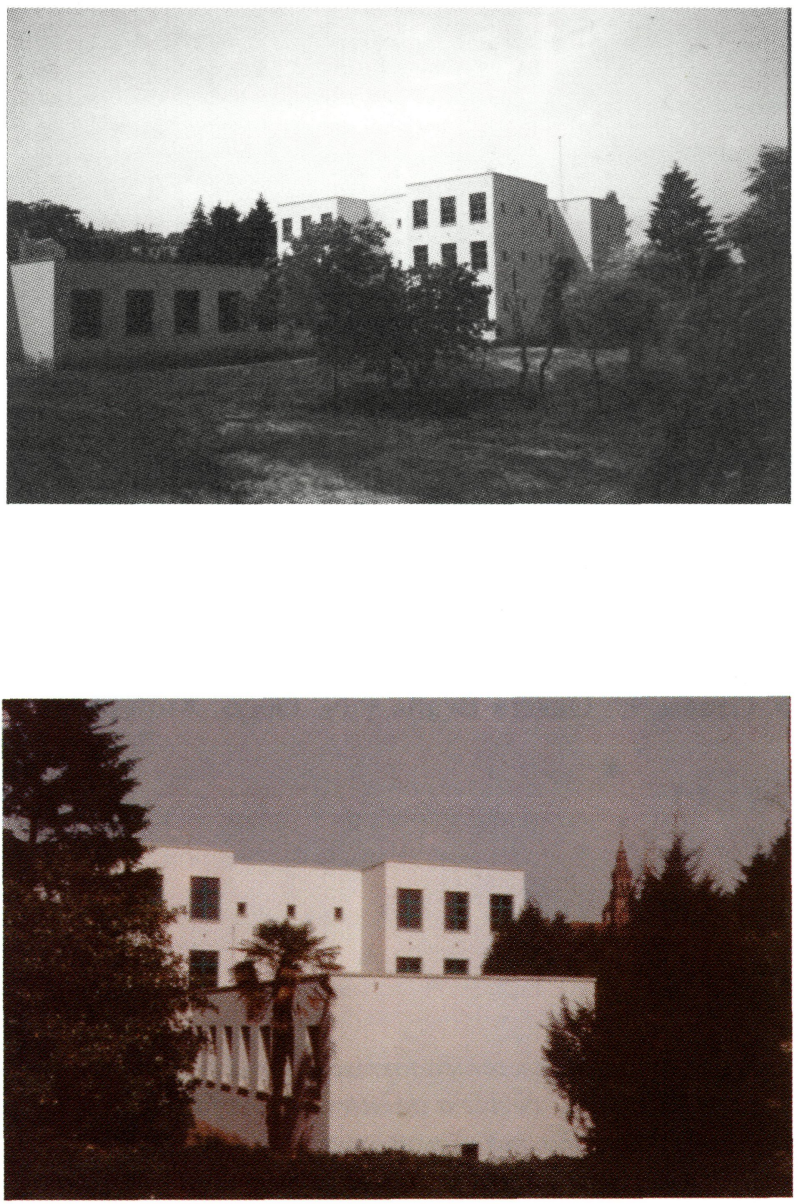

volumétrica, perfectamente integrada con el paisaje que le circunda, han sido algunos de los principales elementos de reflexión y, por lo tanto, de referencia para nuestro trabajo. $\mathrm{Y}$ esto precisamente por la conveniencia dimensional y volumétrica del viejo edificio y para su adecuación respecto a las características especificas del elemento natural en este lugar, en este singular lugar del paisaje extraurbano; la línea divisoria entre la ciudad edificada y el campo que delimita su horizonte, entre el suburbio del Carmen de Abaixo y el bosque que cubre la pequeña colina que está más allá del río Sarela.

Otro importante elemento de reflexión en el trabajo de este proyecto ha sido el sistema constructivo y, por consiguiente, la elección de los materiales de construcción.

Tratándose de un edificio para uso público y teniendo en cuenta, además, el entorno y las condiciones climáticas del lugar, hemos optado por un sistema tradicional que, apartándose en esto de las soluciones habituales de la "villa" de finales de siglo, estuviera en condiciones de recuperar, sin embargo, las características de solidez y duración propias de la construcción en esta región, es decir, de la edificación 


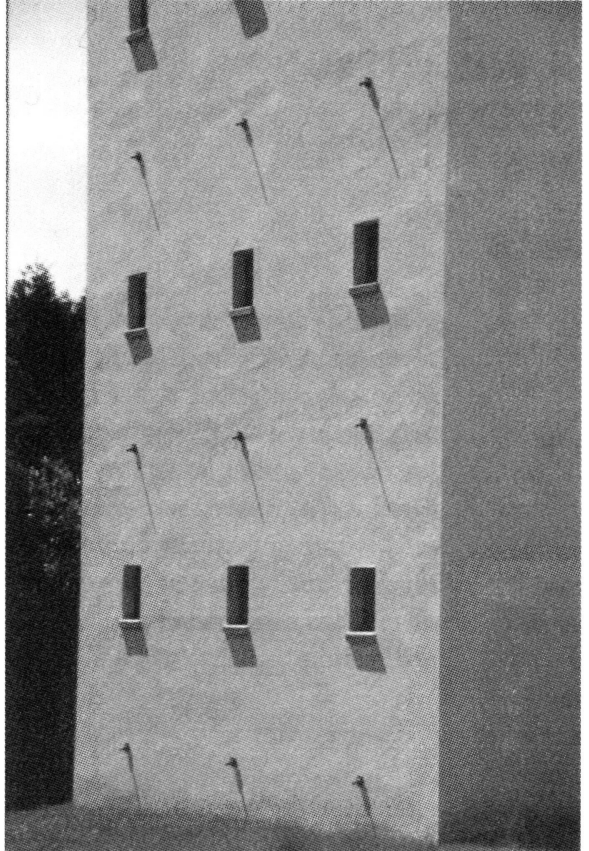

tradicional en piedra que fuera capaz de devolverle, por así decir, el peso, lagravedad, etc..., el valor preponderantemente volumétrico, su forma acabaday definida, como una piedra, como una roca o como una sólida ruina; $\circ$, propiamente, como la estructura elemental misma de un edificio construido piedra sobre piedra.

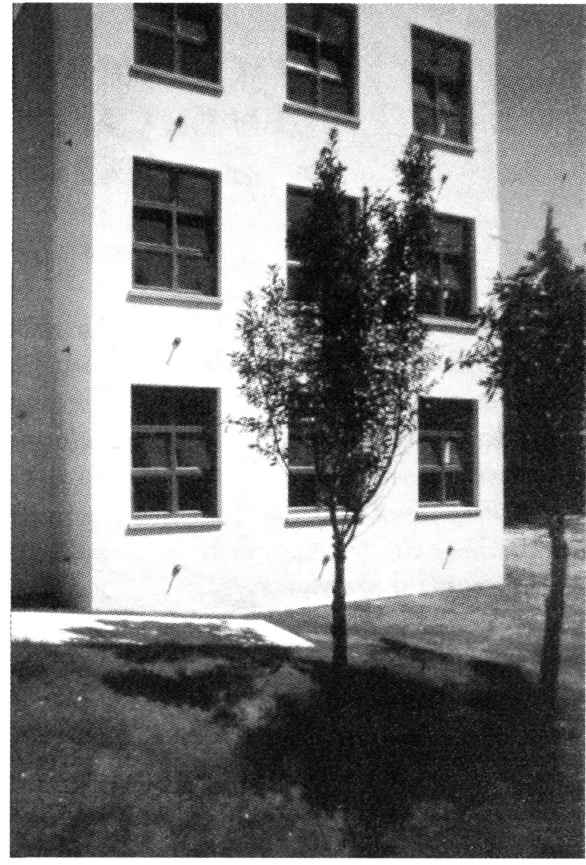

De aquí la elección de muros perimetrales de un cierto espesor y enlucidos, la elección de detalles constructivos y decorativos en piedra desbastada, también éstos de notable espesor (entradas, parapetos y arquitrabes en granito), con puertas y ventanas en madera de dimensiones habituales y con cubierta plana ajardinada.
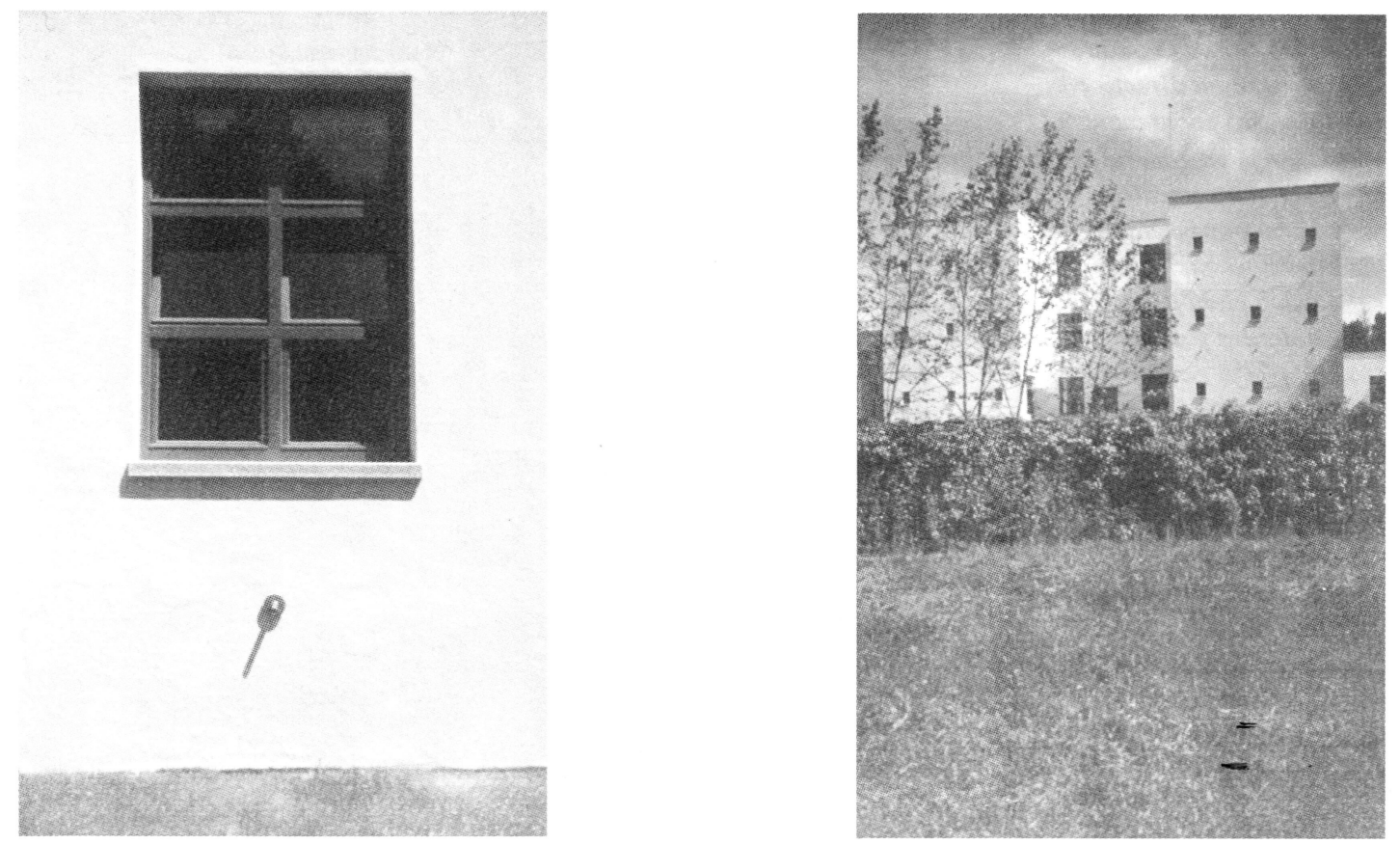